Check for updates

Cite this: RSC Adv., 2018, 8, 33927

\title{
Direct characterization of ion implanted nanopore pyrolytic graphite coatings for molten salt nuclear reactors
}

\author{
Heyao Zhang, (D) † $^{\mathrm{ac}}$ Qiantao Lei, †c $^{\mathrm{bc}}$ Jinliang Song, ${ }^{\text {*c }}$ Min Liu, ${ }^{\mathrm{c}}$ Can Zhang, ${ }^{\mathrm{c}}$ \\ Yantao Gao, ${ }^{c}$ Wenting Zhang, ${ }^{\text {ac }}$ Huihao $\mathrm{Xia}^{\mathrm{c}}$ and Xiangdong $\mathrm{Liu}^{\mathrm{a}}$
}

Nanopore pyrolytic graphite coatings (PyC, average pore size $\sim 64 \mathrm{~nm}$ ) were prepared on graphite to inhibit liquid fluoride salt and $\mathrm{Xe}^{135}$ penetration. The samples were irradiated with $7 \mathrm{MeV} \mathrm{Xe}{ }^{26+}$ to a total peak dose of $0.1,0.5,2.5$ and 5.0 displacements per atom at room temperature to study the irradiation resistance of the PyC. The effect of irradiation on the properties of the graphite was evaluated. With the increase of irradiation dose, the surface morphology of the coatings tends to be smoother. At the total peak dose of $2.5 \mathrm{dpa}$, peeling and spalling on the surface of the samples have been identified, indicating the surface microstructure of the graphite has been damaged by $\mathrm{Xe}^{26+}$ bombardment. Raman results indicated the increase in the degree of disorder and decrease of in-plane crystallite size with the irradiation dose, and the new PyC was more sensitive to irradiation than IG-110 graphite. The nanohardness at peak dose increased with the irradiation dose, but decreased at $2.5 \mathrm{dpa}$. The results of a hardness test also show PyC has a higher irradiation sensitivity.

Received 20th August 2018 Accepted 21st September 2018

DOI: $10.1039 / \mathrm{c} 8 \mathrm{ra06953k}$

rsc.li/rsc-advances precursor at a high temperature of $1800{ }^{\circ} \mathrm{C}$ and low pressure of $\sim 270 \mathrm{~Pa}$ in a vacuum induction furnace..$^{3,9-11,16-18}$

Although PyC meets the MSR requirements for graphite pore size, the relevant data related to its irradiation is not available, and it is not certain whether PyC can tolerate the irradiation environment in the reactor. Therefore, it is necessary to prove whether PyC can be used as a candidate for suitable nuclear graphite in MSR. In this paper, IG-110 (as one of the radiationresistant and commercially available nuclear graphite ${ }^{\mathbf{1 9}}$ ) as a control, the characterization of PyC before and after irradiation visually reflects the degree of damage caused by irradiation at different doses, and then study the irradiation performance of PyC compared with IG-110. Our research helps to select a suitable candidate for protection layer toward fission gas in MSR and contributes to a better understanding of the mechanisms associated with permeability. In this case, the use of the charged-particle irradiation can be useful tool for simulation and estimation of neutron radiation damage, and to compare the irradiation effects of the candidate grades in the same irradiation conditions for the purpose of a selection. ${ }^{\mathbf{2 0 , 2 1}}$ Recently, studies on the effects of $\gamma$-ray irradiation on the structure and mechanical properties of carbon fibers, ${ }^{22,23}$ multiwalled nanotubes ${ }^{24}$ and graphite oxide, ${ }^{25}$ and the synthesis of three-dimensional graphene/polyacrylamide/multi-walled carbon nanotubes architectures by $\gamma$-ray irradiation ${ }^{26}$ have been reported. It was also reported that structural changes of graphene oxide caused by an electron beam, ${ }^{27}$ nuclear graphite was irradiated with $\mathrm{H}^{+}$and $\mathrm{C}^{+20,28}$ and nanopore-isotropic graphite produced from mesocarbon microbeads was
${ }^{a}$ School of Physics, State Key Laboratory of Crystal Materials, Shandong University,
Jinan 250100, China
${ }^{b}$ Institute of Modern Physics, Fudan University, Shanghai 201800, China. E-mail:
jlsong1982@yeah.net; Tel: +862139194258
${ }^{c}$ Key Laboratory of Nuclear Radiation and Nuclear Energy Technology, Shanghai
Institute of Applied Physics, Chinese Academy of Sciences, Shanghai 201800, China
$\dagger$ The two authors contributed equally to this study and share first authorship. 
irradiated with $\mathrm{Xe}^{26+} \cdot{ }^{29}$ However, there were no status of research about the characterization of coatings for molten salt nuclear reactor, and the microstructure and property relation in irradiated PyC are poorly understood.

In this paper, PyC and traditional nuclear graphite IG-110 (Toyo Tanso Co., Kagawa, Japan) ${ }^{9}$ were irradiated with $7 \mathrm{MeV}$ $\mathrm{Xe}^{26+}$ to a total peak dose of $0.1,0.5,2.5$ and 5.0 displacements per atom (dpa) at room temperature to study how the properties and defect changes. The surface morphology was studied by scanning electron microscopy (SEM). Transmission electron microscopy (TEM), Raman spectroscopy, X-ray diffraction (XRD) and selected area electron diffraction (SAED) were used to show the microstructure and crystal structure. Hardness and Young's modulus determined by nanoindenter have performed to identify the changes in the mechanical property of the coatings after irradiation.

\section{Experimental}

\subsection{Specimen preparation and irradiation conditions}

Nanopore PyC (average pore size $\sim 64 \mathrm{~nm}$ ) was prepared by deposition on a IG-110 graphite substrate by a chemical vapor deposition apparatus (vacuum induction furnace), using methane as a precursor and argon as a diluent gas at $1800{ }^{\circ} \mathrm{C}$. The flow rates of methane and argon are 0.25 and $0.60 \mathrm{~m}^{3} \mathrm{~h}^{-1}$, respectively, and the working pressure was $\sim 2$ torr. ${ }^{11}$ The physical properties of the materials are shown in Table 1 . PyC and IG-110 specimens were cut into five pieces of $5 \times 5 \times 1$ $\mathrm{mm}^{3}$ for ${ }^{129} \mathrm{Xe}^{26+}$ irradiation experiment. The IG-110 specimens were polished $\left(0.05 \mu \mathrm{m} \mathrm{Al}_{2} \mathrm{O}_{3}\right)$ and ultrasonic cleaned with the PyC specimens. They were divided into five groups (A, B, C, D and E). Group A without irradiation was kept for comparison. Each piece of group B, C, D and E was irradiated only once. The irradiation of the specimen was carried out with ${ }^{129} \mathrm{Xe}^{26+}$ ion at ambient temperature in a terminal of the $320 \mathrm{kV}$ High-voltage Experimental Platform equipped with an electron cyclotron resonance ion source in the Institute of Modern Physics, Lanzhou, China.

A constant energy ( $7 \mathrm{MeV}$ ) of $\mathrm{Xe}^{26+}$ ions was adopted to obtain four peak doses, corresponding to $0.1,0.5,2.5$ and 5.0 dpa, respectively, according to Stopping and Range of Ions in Matter (SRIM) calculation, ${ }^{30}$ in the depth of $2.3 \mu \mathrm{m}$. While the corresponding surface doses for group B, C, D and E are 0.02, 0.11, 0.55 and 1.25 dpa, respectively, as shown in Fig. 1.

Table 1 Properties of PyC and IG-110 graphite

\begin{tabular}{llr}
\hline Properties & PyC & IG-110 \\
\hline Apparent density $\left(\mathrm{kg} \mathrm{m}^{-3}\right)$ & 1970 & 1770 \\
Average pore size $(\mathrm{nm})$ & 64 & 1840 \\
Graphitization degree $(\%)$ & 44 & 86 \\
Thermal conductivity & $\sim \perp 3, \| 160$ & 116 \\
$\left(298 \mathrm{~K}^{-1} \mathrm{~W} \mathrm{~m}^{-1} \mathrm{~K}^{-1}\right)$ & & \\
Anisotropy ratio & 1.24 (optical anisotropy) & 1.05 \\
Open porosity (\%) & 1.2 & 18.4
\end{tabular}

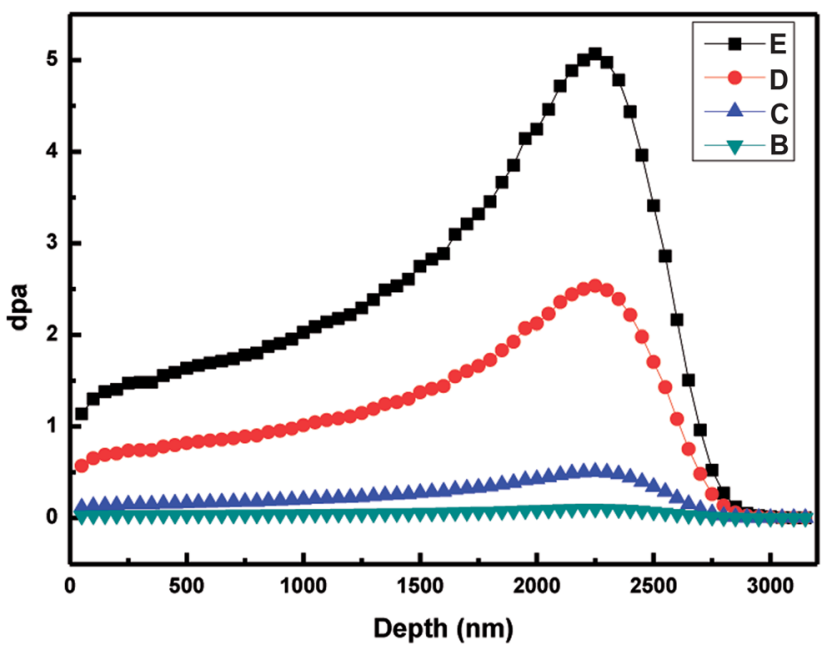

Fig. 1 Depth profiles of damage level (dpa) for group B, C, D and E, according to the estimation with SRIM2008.

\subsection{Characterizations}

Scanning electron microscopy (SEM, LEO 1530VP) was used to monitor the change in the morphological structure of the graphite samples, and their structure before and after irradiation was measured with a Bruker D8 Advance XRD with $\mathrm{Cu}_{\mathrm{K} \alpha 1}$ radiation source $(\lambda=1.5406 \AA)$ conditioned by two $2.5^{\circ}$ Soller slits and a $0.025 \mathrm{~mm}$ Ni mask. The reflected X-ray intensity was collected by a LynxEye XE counter using continuous $\theta-2 \theta$ scans at a tube power of $40 \mathrm{kV} / 40 \mathrm{~mA}$ in a range of $20-70^{\circ}(2 \theta)$, with a step size of $0.02^{\circ}(2 \theta)$ at $0.15 \mathrm{~s}$ intervals. Any changes in the defects induced by irradiation were recorded using a Raman spectrometer (XploRA INV, France) at an excitation wavelength of $532 \mathrm{~nm}$ and effective penetration depth of about $50 \mathrm{~nm}$. Nanoindentation experiments were carried out at room temperature using a diamond Berkovich indenter (triangular based pyramid) in continuous stiffness measurement mode using a G200 nanoindenter with a penetration depth of $3 \mu \mathrm{m}$. A FEI Tecnai $\mathrm{G}^{2} \mathrm{~F} 20$ microscope operated at $200 \mathrm{kV}$ was used for TEM analysis of the samples. In order to clearly show the changes of each sample before and after irradiation at different doses, and to compare the irradiation resistance of PyC and IG110 samples under different irradiation conditions, the irradiated PyC and IG-110 samples, together with the irradiated PyC and IG-110 samples at peak doses of 0.1, 0.5, 2.5 and 5.0 dpa, were characterized by SEM, TEM, XRD, Raman spectrometer and nanoindentation, respectively.

\section{Results and discussion}

\subsection{Crystal structure}

$\mathrm{XRD}$ is an effective tool to determine the graphite crystal structure and parameters that affect its performance in nuclear applications. ${ }^{31-34}$ In our previous study, the diffraction peaks of PyC are broader than their IG-110 counterparts, and the center of the (002) peak is displaced and the angle becomes smaller, which demonstrates that the $\mathrm{PyC}$ has a lower degree of 

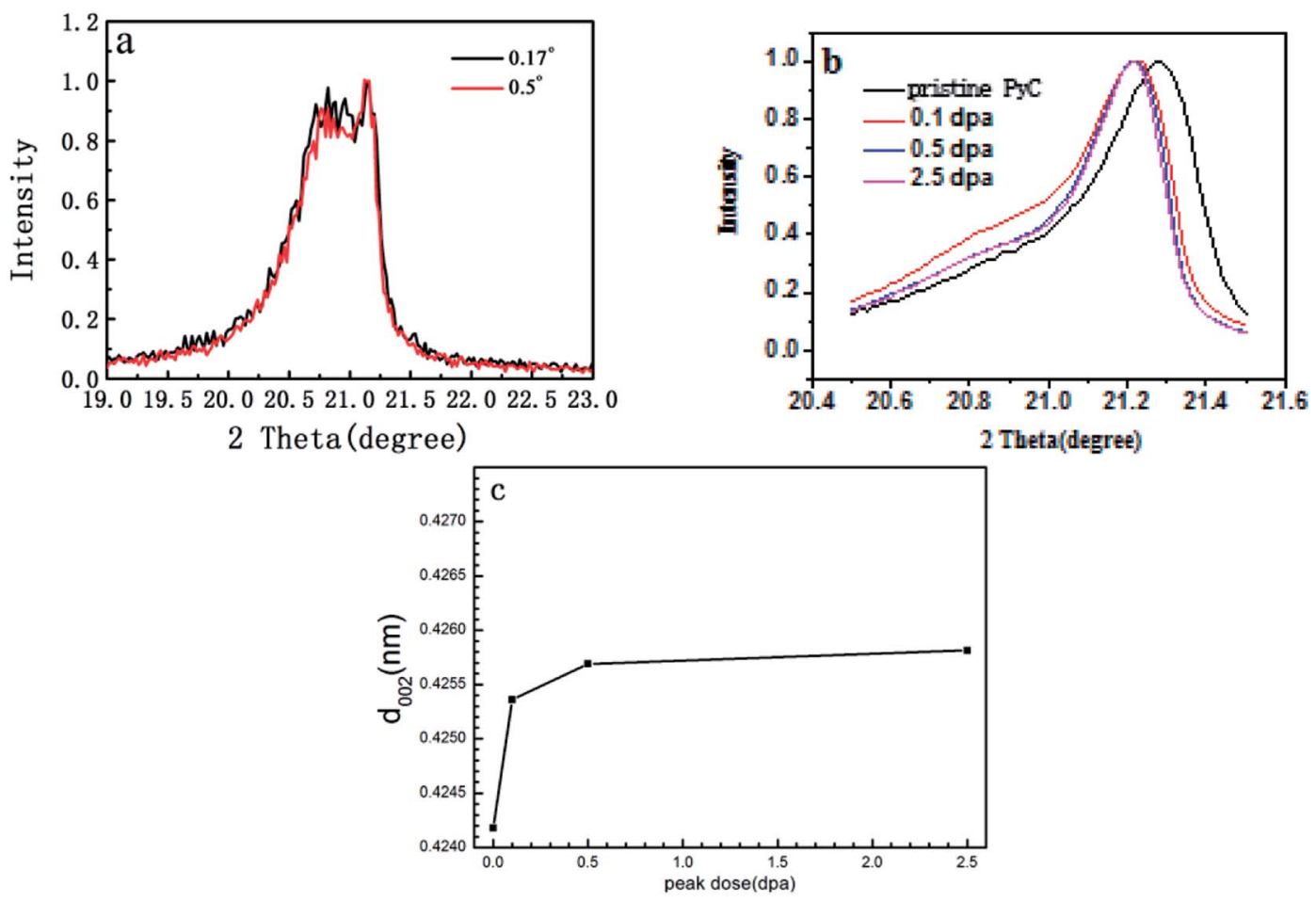

Fig. 2 XRD pattern of pristine PyC.

graphitization than IG-110. ${ }^{9}$ Fig. 2a shows the XRD patterns of pristine PyC on IG-110 nuclear graphite. In order to reduce the influence of the graphite matrix, two incidence angles of $0.17^{\circ}$ and $0.5^{\circ}$ have been chosen to study the matrix effects. As shown in Fig. 2a, the XRD pattern and peak center (002) of $0.5^{\circ}$ have matched well with those of $0.17^{\circ}$. Thus, the angle of incidence is fixed at $0.17^{\circ}$, which could eliminate the influence of the graphite matrix structure. Fig. 2b shows that the (002) peaks of PyC shift from $21.28^{\circ}$ to smaller angles of $21.24^{\circ}$ even under the $0.1 \mathrm{dpa}$ and no more shift of angle for the same samples even irradiated at highest dose of $5 \mathrm{dpa}$. The irradiated diffraction peaks of PyC are broader than their corresponding counterparts of IG-110 nuclear graphite and the higher $\mathrm{Xe}^{26+}$ irradiation dose did not cause the layer spacing change that could be detected. Fig. 2c shows the variation of $d_{002}$, calculated from Bragg's law. After irradiation at $0.1 \mathrm{dpa}, d_{002}$ increased sharply from 0.424 to $0.425 \mathrm{~nm}$ and slowly increased as the irradiation dose increased. The change in layer spacing is attributed to the accumulation of vacant atoms between the basal planes caused by irradiation (the phenomenon can be seen from the TEM image).

\subsection{Morphology changes}

3.2.1 Changes of surface morphology. Fig. 3 is the fieldemission SEM micrographs of cleaned samples, showing the surface morphology changes of the PyC after different irradiation dose, with IG-110 nuclear graphite as a comparison. The IG-110 graphite is not fit for MSR for the pores are generally larger than $1 \mu \mathrm{m}$, which could lead to molten salt impregnation and gas diffusion. ${ }^{9}$ The surface morphology of PyC is pretty uniform and dense, which consists of fine grains with the size about $0.5-3 \mu \mathrm{m}$, and it is the typical characteristics of pyrolytic carbon growth cone appearance. SEM micrographs show few flaws or cracks on the surface of the coatings and it has good sealing effect to protect the nuclear graphite against the permeation of molten fluoride salts and the diffusion of fission gases. ${ }^{35}$ Fig. 3a-d show the graphite surface becoming smoother with the increase of irradiation dose. This kind of changes has been found in other pyrolytic carbon materials after irradiation. ${ }^{36,37}$ At the surface dose of $0.55 \mathrm{dpa}$, the PyC surface was peeled off from the graphite surface. The peeled coatings become so smooth that the edge of the two parts cannot be identified. At the surface dose of $1.1 \mathrm{dpa}$, there are no visible typical pyrolytic carbon spherical caps on the surface of the peeling part. However, there is no peeling for the surface of IG110 , and it tends to be smoother after different dose irradiation. It is speculated that high ion dose of ${ }^{129} \mathrm{Xe}^{26+}$ in our work may be responsible for the evolution of morphological differences.

3.2.2 TEM microstructure analysis. Raman spectroscopic analysis (in the next section) showed that the surface doses of $0.11 \mathrm{dpa}$ and $0.55 \mathrm{dpa}$ were the doses at which the PyC and IG110 Raman spectra reached saturation or supersaturation, respectively. In order to more clearly compare the degree of damage of PyC and IG-110 and the difference in radiation resistance, irradiated samples at the surface irradiation dose of 0.11 and 0.55 dpa were used for TEM characterization. SEM microscopy on the cross-section of PyC and graphite matrix interface exhibits a wave-like layered structure with $20 \mu \mathrm{m}$ in thickness based on IG-110 as shown in Fig. 4a. High resolution TEM (HRTEM) image shows that the structure of PyC is turbostratic aromatic layer. There are numerous cracks in IG-110, while there is no crack observed at the coating interfaces as 


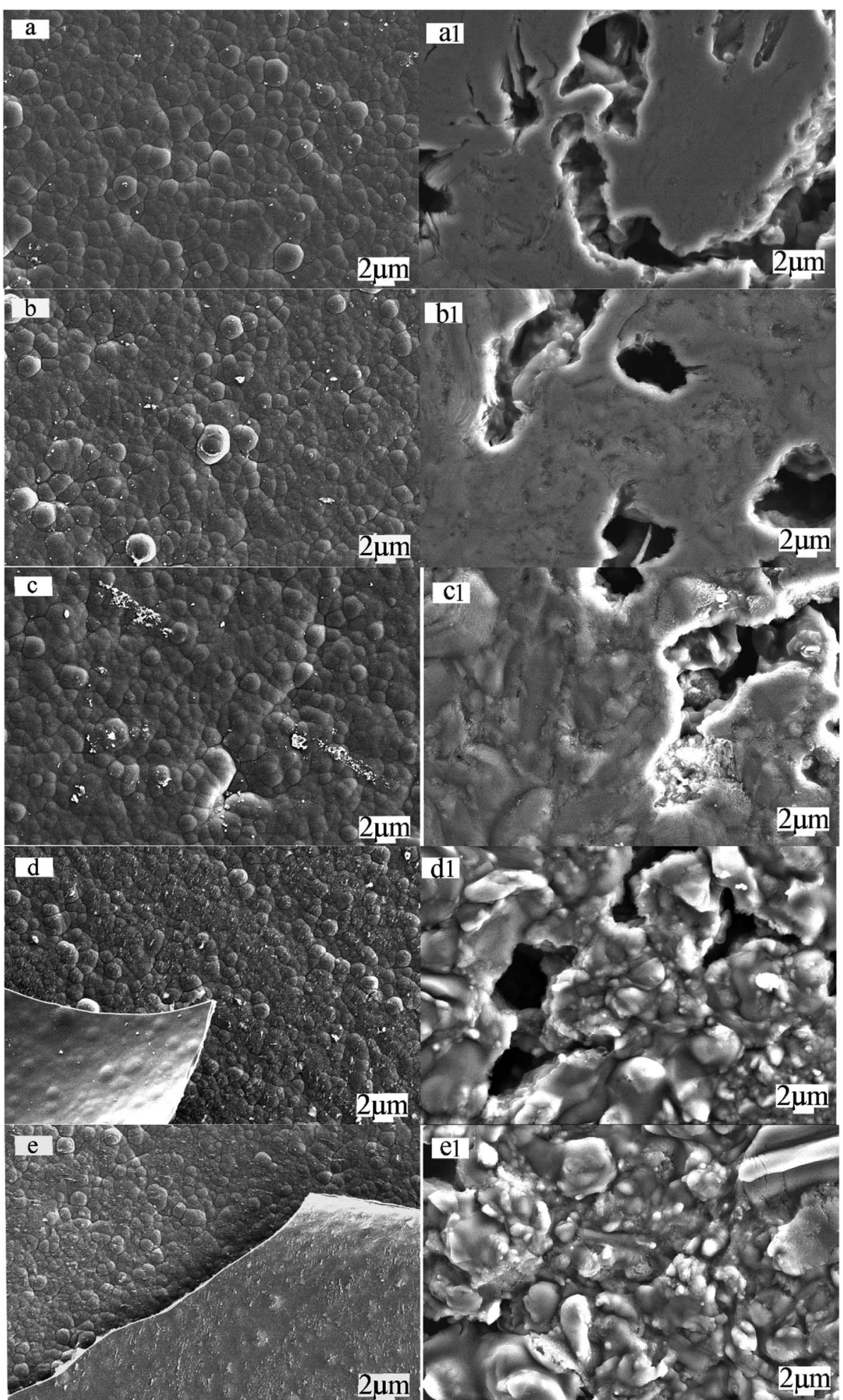

Fig. 3 SEM micrographs of (a) pristine PyC, irradiated PyC at surface dose of (b) 0.02 , (c) 0.11 , (d) 0.55 and (e) 1.25 dpa; (a1) pristine IG-110, irradiated IG-110 at surface dose of (b1) 0.02, (c1) 0.11, (d1) 0.55 and (e1) $1.25 \mathrm{dpa}$

TEM microscopy on cross-sections shown in Fig. 4b. The graphite layers of the PyC are stacked one above the other with a rotational disorder. Dense microstructure with the layer tightly bonding together inhibits the gas penetration of graphite, which performs well in the protection of nuclear graphite. Fig. 4c and d are respectively the bright and dark field HRTEM images of coatings on the graphite matrix. As to the graphite coatings, most smooth laminar structure exists in the initial graphite surface during the deposition process, which fluctuates greatly with various shapes of different grain size and 

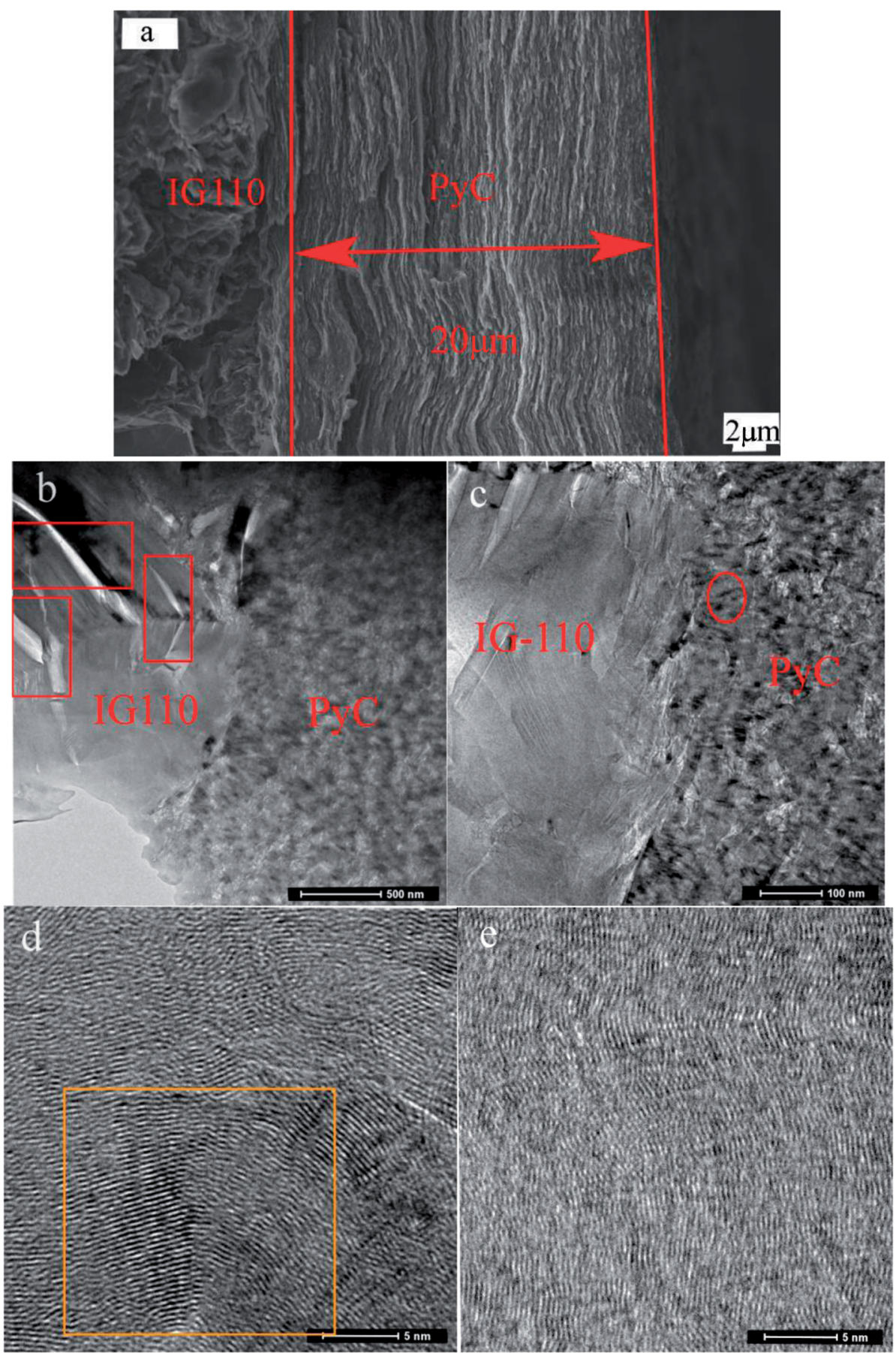

Fig. 4 (a) Field-emission SEM micrographs of pristine PyC cross section, TEM micrographs of (b) interface region between PyC and IG-110, (c) interface region at high magnification, (d) HRTEM image near the interface and (e) HRTEM image of surface.

orientation as shown in Fig. 4d. And the crystal structure of the coatings is relatively more disorder. While rough laminar structure coatings exist in the surface area formed during the later period, and the wave-like layered structure are relatively smoother. The order of crystal structure is better than the smooth laminar as shown in Fig. $4 \mathrm{~d}$.

The irradiation induced microstructure changes have a profound impact on the physical properties such as the Young's modulus, fracture strength, electrical and thermal conductivity of the graphite. ${ }^{38,39}$ SAED and HRTEM were used in different irradiation dose of 0.11 and 0.55 dpa to get the microstructure evolution information with the increase of irradiation dose. Fig. 5 shows the structure change of the coating on the graphite irradiated at about $0.11 \mathrm{dpa}$. Bright and dark TEM fields show the different contrast between the areas before and after irradiation. Dark field TEM can give better evidence for material with orientation. In the dark field TEM image (Fig. 5b), bright area of PyC has a (002) preferred orientation, hole and the disordered carbon part is black. Bright-field image (Fig. 5c) shows the cone pyrolytic carbon coating 
structure. Combining with Fig. 5a-c, a $3 \mu \mathrm{m}$ irradiated blurred layer could be identified. The ion irradiation made the PyC particle boundary become smooth.

Fig. $5 \mathrm{~d}$ is the selected area diffraction of TEM for the irradiated area on the samples. The SAED map is blurry, which related to the disorder caused by irradiation. In order to observe the defects along with the change of the depth caused by irradiation, Fig. 5e and f respectively shows the HRTEM of the area on the surface and the irradiation area inner the irradiated layers at the surface dose of $0.11 \mathrm{dpa}$, indicating the bending and dislocation increased significantly compared with the unirradiated samples. The result is similar to the in situ electron beam irradiation. The smaller crystallite size and more dislocation in the inner part indicate more serious damage caused by irradiation than on the surface of the coatings, which is consistent with SRIM simulation. Fig. $5 \mathrm{~g}$ and $\mathrm{h}$ are the graphite and PyC coating interface magnification images, respectively. The dark-field TEM image (Fig. 5g) shows the original texture structure has been damaged and the corresponding bright-field TEM image (Fig. 5h) shows the texture is smooth.

TEM microscopy on the cross-section of PyC at the surface dose of 0.55 dpa has been shown in Fig. 6. The implanted energy is $320 \mathrm{kV}$ and the $3 \mu \mathrm{m}$ irradiation blurred layer as mentioned above at $0.11 \mathrm{dpa}$ has also be detected. As shown in the TEM image in Fig. 6b, the dark-field TEM image shows the original texture structure was damaged. The corresponding bright-field TEM image (Fig. 6c) shows the texture is smoother than the sample irradiated at $0.11 \mathrm{dpa}$. The SAED indicates the disorder has increased due to the irradiation and the irradiated area have become sharply blurred since the particulate matter tends to become round as Fig. 6d shows. Fig. 6e and $\mathrm{f}$ are respectively the HRTEM of the area on the surface and in the inner part of the irradiated layers, which shows the bending and dislocation significantly increased compared to the $0.11 \mathrm{dpa}$ doss irradiated samples. HRTEM images recorded from the inner part of the irradiated layers shows smaller crystallite size and more dislocation as shown in Fig. 6f. It shows that irradiation in the inner part is more serious than the surface layer, which is consistent with SRIM simulation at $0.11 \mathrm{dpa}$.

\subsection{Raman spectroscopic analysis}

Fig. 7 shows the Raman spectra with linear background subtraction of PyC coatings (a) virgin state, (b and c) after 0.02, 0.11 dpa Xe surface irradiation and IG-110 graphite matrix $\left(\mathrm{a}_{1}\right)$ virgin graphite, $\left(\mathrm{b}_{1}-\mathrm{e}_{1}\right)$ after $0.02,0.11,0.55,1.25 \mathrm{dpa}$ Xe surface irradiation. The main features in the typical Raman spectrum of graphite are two sharp peak, the G peak at $1580 \mathrm{~cm}^{-1}$ and the D peak around $1360 \mathrm{~cm}^{-1}$. The $\mathrm{D}$ peak is Raman active for $\mathrm{sp}^{2}$ carbon networks and is inherent in graphite. ${ }^{\mathbf{4 0 1}}$ The D mode is associated with the double-resonant Raman scattering involving the spatial disorder, electrons and TO phonons near the $K$ point of Brillouin zone, and is a sign of the presence of many defects. ${ }^{42}$ As respectively shown in Fig. $7 a$ and $a_{1}$, the similar profile exists in the Raman spectra of unimplanted PyC coating and IG-110 graphite, and it also shows more defects exist in IG-110 graphitic structure compared with that in PyC coatings. ${ }^{43}$ After $\mathrm{Xe}^{26+}$ ion implantation, the intensity of $\mathrm{D}$ peak in the PyC Raman spectrum increases rapidly at the begining, as shown in Fig. 7b and $b_{1}$, which differs from IG-110 graphite. In the Raman spectrum of PyC, the full width at half maximum (FWHM) of both D and G peaks gradually increased and caused the spectrum is asymmetric with a broad shape and both distinguishable main peaks overlap each other indistinguishably, with increasing of irradiation dose. While, all of the changes have stopped at $0.55 \mathrm{dpa}$ and nearly kept the same shape under the higher dose. Although a similar growing trends of FWHM with irradiation dose also appears in the Raman spectrum of IG-110 graphite, changes in the former are more sensitive to the increase of irradiation dose. This is a reflected in the slower change in the later and the greater dose (1.25 dpa) that keep the graph constant, as shown in Fig. 5. With the increase of irradiation dose, the coatings were peeled off from the graphite matrix at $0.55 \mathrm{dpa}$ as the SEM shown, so there are no obvious change that could be detected in the Raman spectrum even up to $1.25 \mathrm{dpa}$. It also can explain why Fig. 7c is similar with Fig. $7 \mathrm{e}_{1}$. The phenomenon indicates the PyC showed higher irradiation sensitivity for the change in crystallinity than that of IG-110. Meanwhile it also suggests that the irradiation of heavy ion ( $\mathrm{Xe}^{26+}$ ion) can bring on a more serious irradiation damage compared with that of light ions, e.g., $\mathrm{N}^{+}$ ion $^{44}$ and $\mathrm{C}^{+}$ion. ${ }^{45}$

After the analyzation of multicomponent spectral, there are two additional new peaks around $1150\left(\mathrm{v}_{1}\right.$ peak) and $1500 \mathrm{~cm}^{-1}$ ( $\mathrm{v}_{2}$ peak), in addition to two well-known peaks ( $\mathrm{G}$ and $\mathrm{D}$ peak). Following the work of Ferrari and Robertson, the ratio of the $\mathrm{D}$ and $\mathrm{G}$ band intensities $\left(I_{\mathrm{D}} / I_{\mathrm{G}}\right)$ is inversely proportional to the inplane crystallite sizes $L_{\mathrm{a}}$ and it will increase with increasing disorder. ${ }^{46,47}$ The $I_{\mathrm{D}} / I_{\mathrm{G}}$ presents an upward trend with the increasing of irradiation dose, as shown in Fig. 7, implying the increase of defects and the decreasing for the degree of in-plane order in the graphitic structure. ${ }^{42}$ The crystallite sizes of the PyC surface are estimated to be decreased from 12.01 to $3.76 \mathrm{~nm}$, caused by the surface irradiation of $0.02 \mathrm{dpa}$, and then decreased to 3.59 at 0.11 dpa surface irradiation.

According to the conclusion reached by Ferrari et al. and it has been widely accepted now that $\mathrm{v}_{1}$ and $\mathrm{v}_{2}$ peaks are companion modes as-signed to trans-polyacetylene (trans-PA) lying in grain boundaries. ${ }^{48}$ Noticeably, it can be seen from Fig. 8a that the trans-PA indeed exists in our non-implanted specimen. Subsequently, implanted by a low irradiation dose of $0.11 \mathrm{dpa}$, the ratio of $I_{\mathrm{V}_{1}} / I_{\mathrm{G}}$ and $I_{\mathrm{V}_{2}} / I_{\mathrm{G}}$ increase obviously and then nearly reach saturation point, seen in Fig. 5 . The increase of $I_{\mathrm{V}_{1}} / I_{\mathrm{G}}$ and $I_{\mathrm{V}_{2}} / I_{\mathrm{G}}$ is caused by the enabling environment of $\mathrm{C}=\mathrm{C}$ chain stretching and $\mathrm{C}-\mathrm{H}$ wagging modes generated by ion implantation. ${ }^{49}$ Parallel evolution rule of the relative intensity of $v_{1}$ and $v_{2}$ modes with the increasing irradiation dose also appeared in other PyC system. ${ }^{44}$ With growing irradiation damage dose up to $0.55 \mathrm{dpa}$, the threshold of hydrogen content in PyC specimens contributes to the saturation of $I_{\mathrm{v}_{1}} / I_{\mathrm{G}}$ and $I_{\mathrm{V}_{2}} /$ $I_{\mathrm{G}}$, due to the close connection between the $\mathrm{v}_{1}$ and $\mathrm{v}_{2}$ modes of trans-PA and the existence of hydrogen. ${ }^{49} I_{\mathrm{V}_{1}} / I_{\mathrm{G}}$ and $I_{\mathrm{V}_{2}} / I_{\mathrm{G}}$ in PyC in IG-110 is much smaller than that in PyC, so it can be estimated that there would be more hydrogen in PyC. 

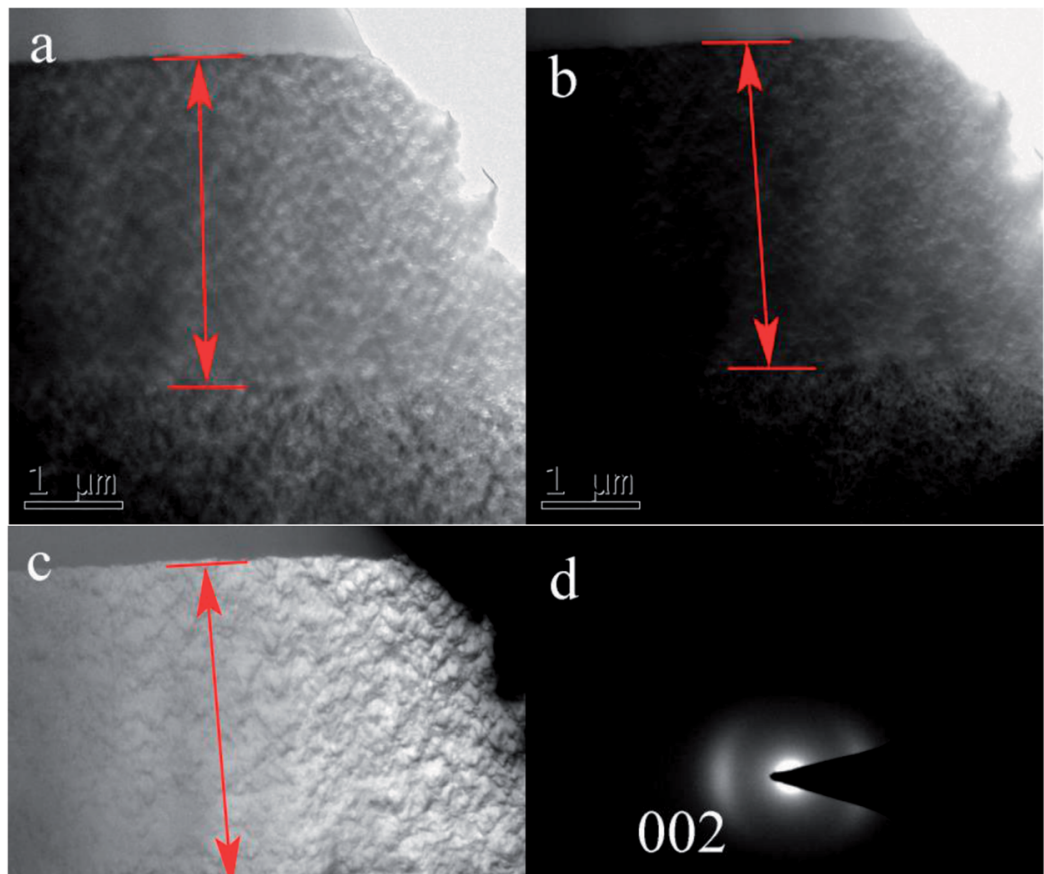

\section{$5-1 /$ [I[I]}

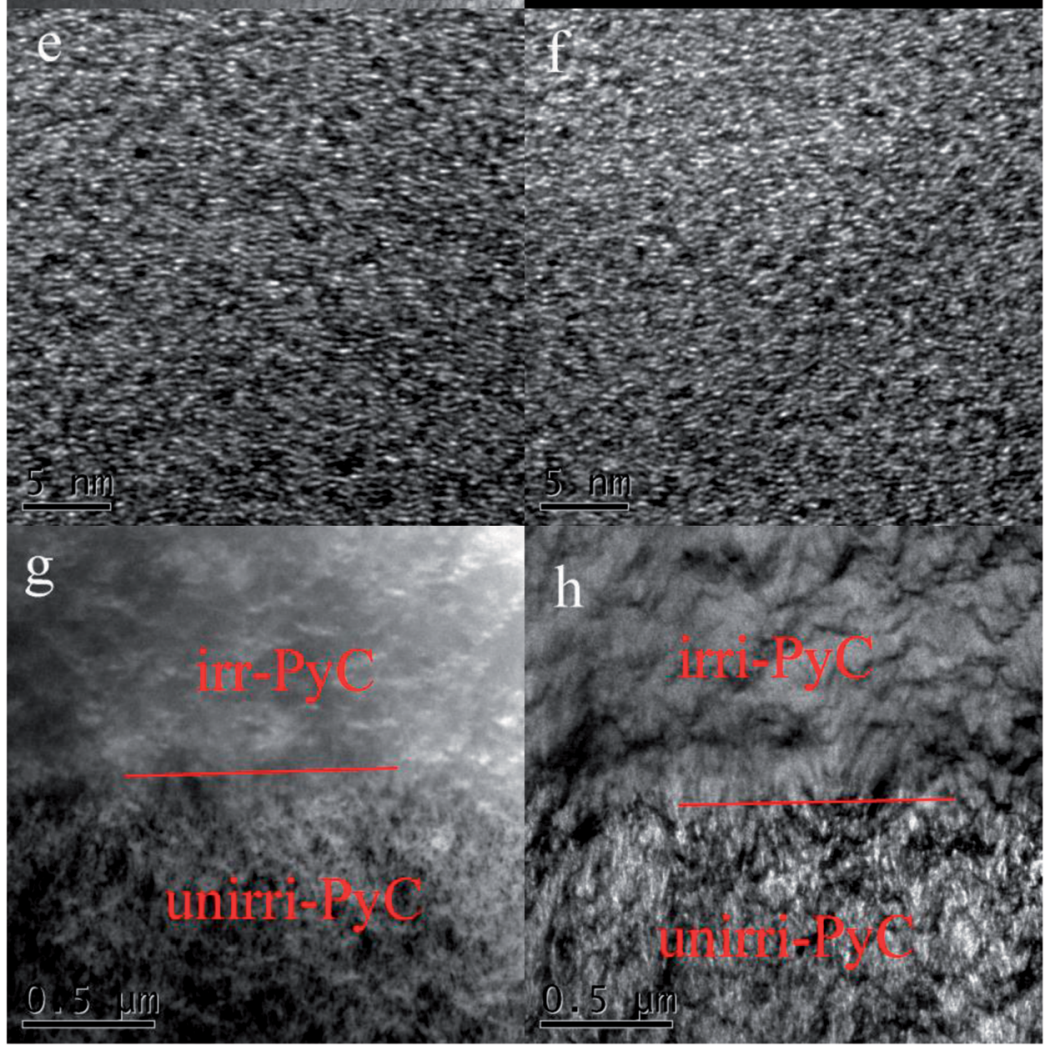

Fig. 5 TEM micrographs of (a) unirradiated PyC cross section between PyC and IG-110, (b) bright-field, (c) dark field, (d) selected area of electron diffraction, (e) HRTEM image of surface, ( $f$ ) HRTEM image near cross section and (g) dark field TEM of interface region at high magnification, (h) bright-field TEM of interface region at high magnification. 


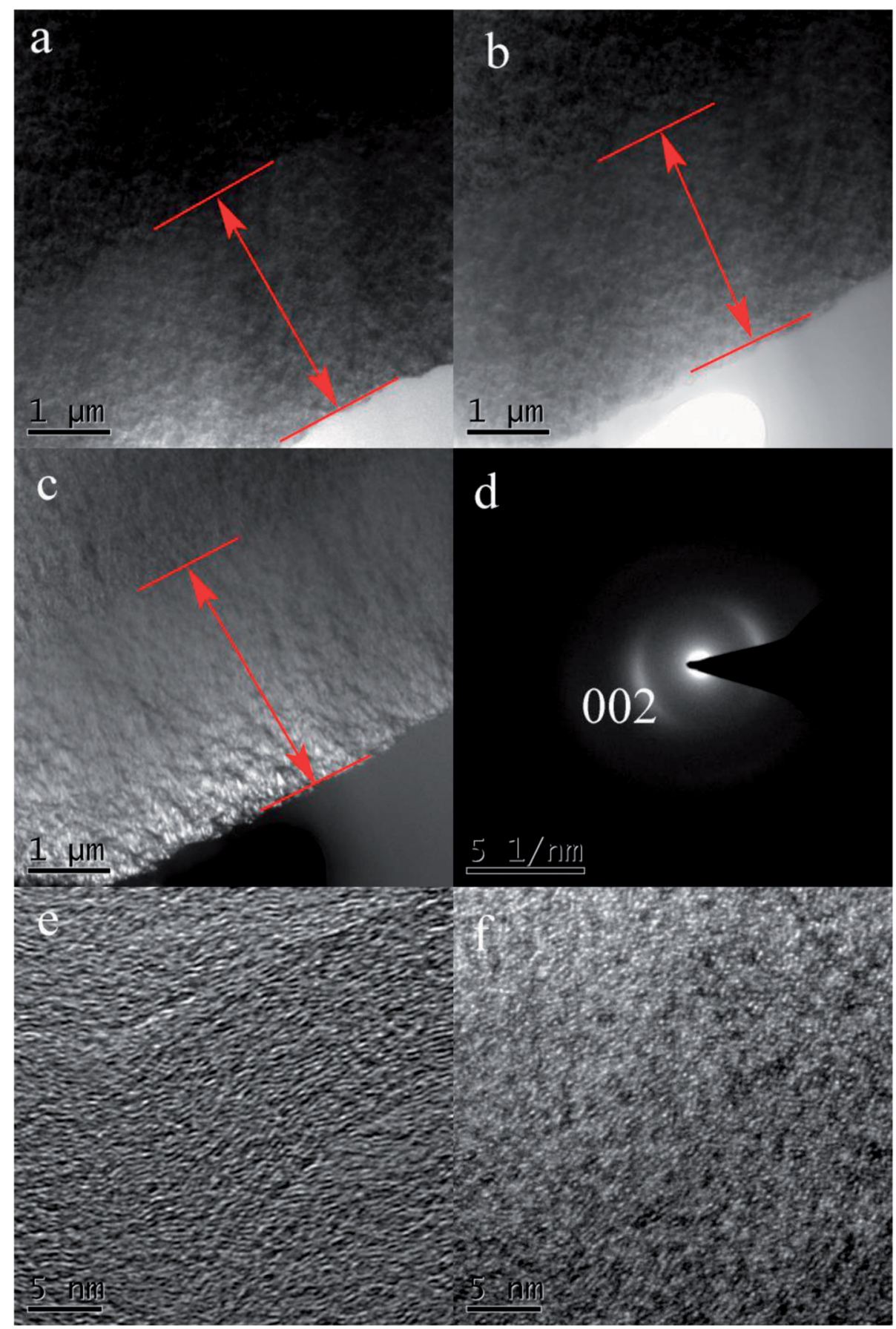

Fig. 6 TEM micrographs of (a) pristine PyC cross section between PyC and IG-110, (b) bright-field, (c) dark field, (d) SEAD of irradiated samples at the surface irradiation dose of $0.55 \mathrm{dpa}$, (e) HRTEM image of surface and (f) HRTEM image of inner cross section.

\subsection{Irradiation effect on mechanical properties}

Fig. 9 shows the dependence of hardness and Young's modulus versus the penetration depth. The penetration depth of the indenter was $3 \mu \mathrm{m}$, and the data points were averaged from the results of 20 tests. The error bar of the data was the standard deviation of the distribution of 20 tests. Before the irradiation (the purple red line in Fig. 9a), the hardness and Young's modulus remained constant from 2 to $3 \mu \mathrm{m}$.
Fig. 9a shows that the average hardness of PyC increased after the irradiation. At the peak dose of 0.5 dpa irradiation (blue line), the hardness of PyC quickly increased and reached the highest value as shown in Fig. 9a, the hardness (400-900) reach five times of the original samples and the hardness (2400$2900)$ reach 1.75 times compared to the original samples. The hardness increased to the original value and was consistent with the results obtained from the neutron irradiation experiments, indicating an obvious irradiation-hardening 

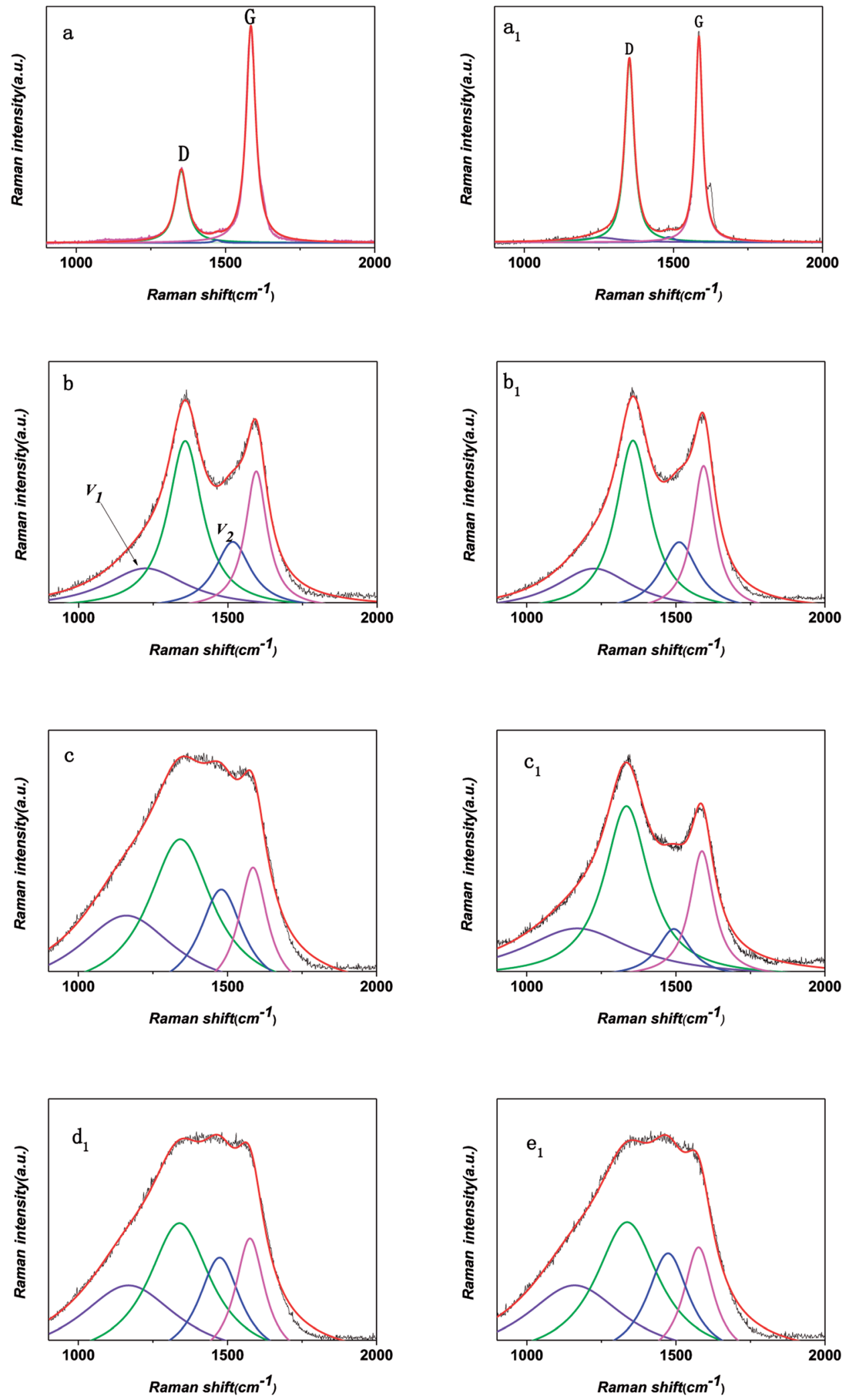

Fig. 7 Raman spectra with linear background subtraction of PyC coatings (a) virgin state, (b and c) after 0.02, 0.11 dpa Xe surface irradiation; IG110 graphite matrix $\left(a_{1}\right)$ virgin graphite, $\left(b_{1}-e_{1}\right)$ after $0.02,0.11,0.55,1.25$ dpa Xe surface irradiation. All spectra were fitted with four Lorentz line shape fitting. 

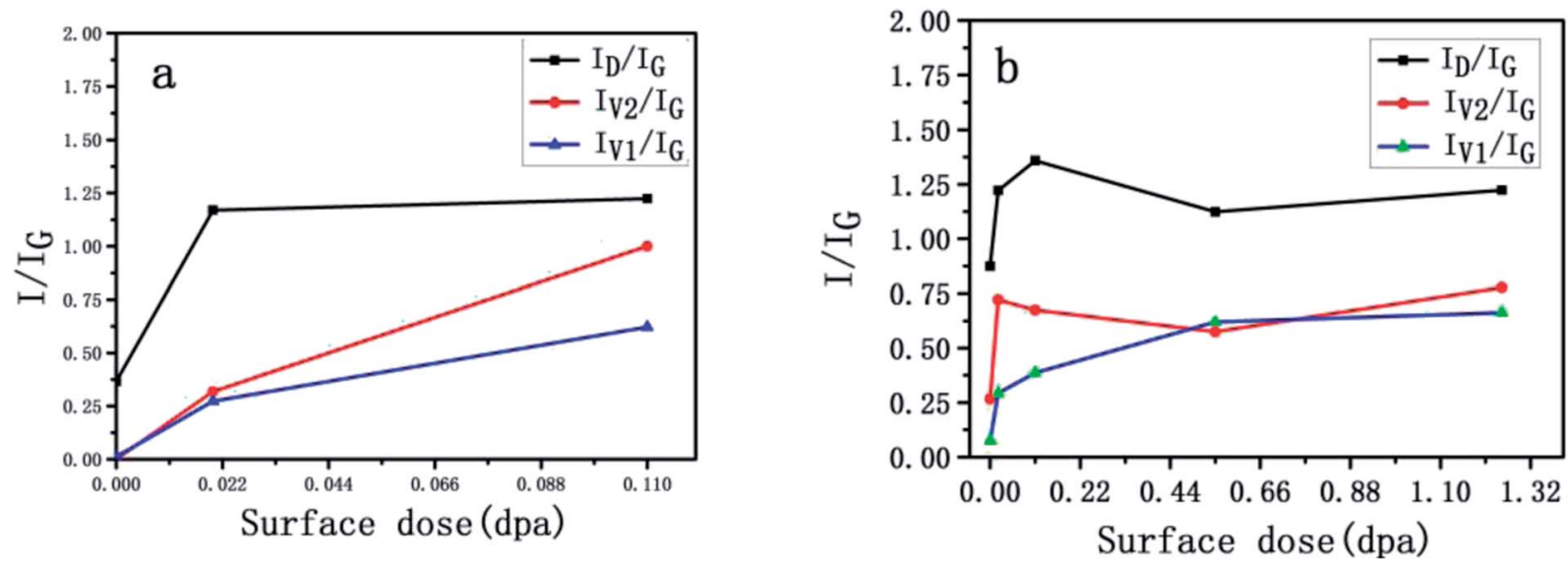

Fig. 8 Intensity ratio of Raman peaks $\left(I_{\mathrm{D}} / I_{\mathrm{G}}, I_{\mathrm{v}_{1}} / I_{\mathrm{G}}\right.$ and $\left.I_{\mathrm{v}_{2}} / I_{\mathrm{G}}\right)$ (a) PyC (b) IG-110 as functions of fluence.
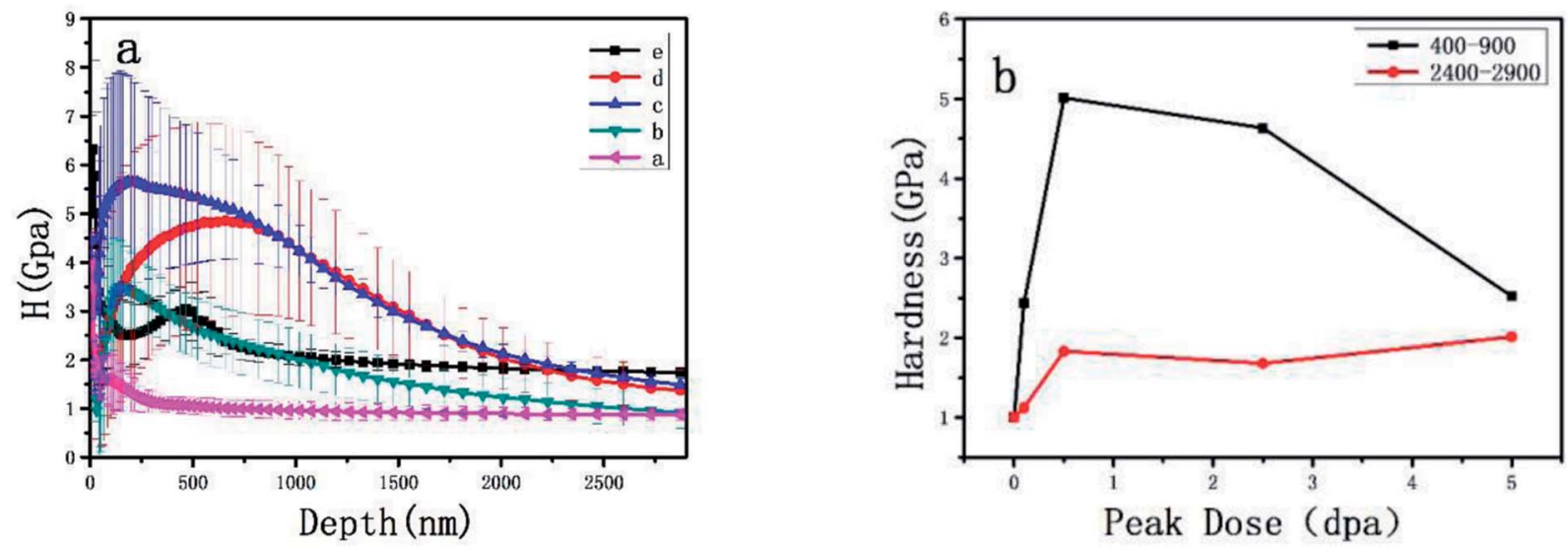

Fig. 9 Variation in (a) hardness of PyC versus indentation depth before and after $7 \mathrm{MeV}$ Xe irradiation (group a without irradiation was kept for comparison. Each piece of group b, c, d and e was irradiated at 0.1, 0.5, 2.5 and 5.0 dpa, respectively), (b) is for 400-900 nm and 2400-2900 nm.

phenomenon. At the peak dose of $5 \mathrm{dpa}$, the hardness decreased quickly to about two times of the original, maybe it count to the pealing of the coatings, and SEM micrographs provide the evidence in Fig. 3e.

The mechanical property increase is presumably caused by pinning of the basal plane dislocations as observed in single crystals. In un-irradiated specimens, a high density of basal dislocation is generally found. The effect of irradiation is to increase dislocations and point defects as shown in Fig. 5. The explanation of the elastic modulus enhancement given by Kelly is that irradiation introduces point defects that pin dislocations. The rapid accumulation of the interstitial defects from the Raman results and the increase in basal plane dislocations observed by the TEM images after the irradiation supports Kelly's explanation.

\section{Conclusions}

Nanopores PyC was prepared and has been irradiated with 7 $\mathrm{MeV} \mathrm{Xe}{ }^{26+}$ compared with IG-110 graphite. Raman results revealed a significant increase of $I_{\mathrm{D}} / I_{\mathrm{G}}$ ratio after Xe implantation, predicting the increase in disorder near the surface. The increase in disorder is also confirmed by TEM. Such sections allow the imaging of a gradient of structural changes from virgin graphite up to a highly disordered carbon near the surface, and the images show a strong decrease of the crystallite size. The IG-110 experienced a larger decrease in the crystallite size and the PyC showed higher irradiation sensitivity for the crystallinity change. At the total peak dose of $2.5 \mathrm{dpa}$, a peeling and spalling phenomenon appeared on the PyC, indicating the surface microstructure of the graphite damaged by $\mathrm{Xe}^{26+}$ bombardment and the new PyC also shows higher irradiation sensitivity than that of IG-110. The results of hardness test also show higher irradiation sensitivity for the PyC. Although PyC has good sealing properties, it is more sensitive to irradiation than IG-110 and cannot tolerate the irradiation compared to the IG-110 graphite, and is not the best choice for sealing the nuclear graphite for MSR.

\section{Author contribution}

Heyao Zhang wrote the paper and performed the main experiments; Jinliang Song helped with the manuscript revision; Wenting Zhang designed the research; Qiantao Lei and Min Liu 
contributed to specimen preparation; Can Zhang and Yantao Gao contributed to SEM, TEM, Raman spectroscopic analysis and Nanoindentation measurements works; Huihao Xia and Xiangdong Liu participated in the discussion.

\section{Conflicts of interest}

There are no conflicts of interest to declare.

\section{Acknowledgements}

The work was sponsored by the National Natural Science Foundation of China (No. 51602336), Natural Science Foundation of Shanghai (No. 16ZR1443400), the National Natural Science Foundation of China (No. U1632268, 51602335, 51572274, 11075097, 11375108 and 11775134), Scientific Instrument and Equipment Development Project CAS Foundation (Grant \# Y828011031), Natural Science Foundation of Shandong (No. ZR2016CM02).

\section{References}

1 A Technology Roadmap for Generation IV Nuclear Energy Systems, USDOE/GIG-002-00 report, https:/www.gen-4.org/ PDFs/GenIVRoadmap.pdf, The U.S. DOE Nuclear Research Advisory Committee and the Generation IV International Forum, 2002, vol. 11, p. 33.

2 J. Uhlír, Chemistry and technology of molten salt reactorshistory and perspectives, J. Nucl. Mater., 2007, 360, 6-11.

3 E. S. Bettis, S. S. Kirslis, W. H. Cook, H. E. Mccoy, W. P. Eatherly and A. M. Perry, et al., Graphite behavior and its effects on MSBR performance, Oak Ridge National Laboratory, USA, 1969, ORNL-TM-2136, 34-41.

4 M. W. Rosenthal, R. B. Briggs and P. N. Haubenreich, Molten salt reactor program semiannual progress report, Oak Ridge National Laboratory, USA, 1971, ORNL-4728, 118-121.

5 M. W. Rosenthal, P. N. Haubenreich and R. B. Briggs, The Development status of molten-salt breeder reactors, Oak Ridge National Laboratory, USA, 1972, ORNL-4812,175-193, 273-290.

6 A. P. Malinauskas, J. L. Rutherford and R. B. Evans, Gas transport in MSRE moderator graphite: part i review of theory and counter diffusion experiments, Oak Ridge National Laboratory, USA, 1967, ORNL-4148, 12-37.

7 R. B. Evans, J. L. Rutherford and A. P. Malinauskas, Gas transport in MSRE moderator graphite: parts ii effects of impregnation and iii variation of flow properties, Oak Ridge National Laboratory, USA, 1969, ORNL-4389, 14-40.

8 H. E. McCoy, R. L. Beatty, W. H. Cook, R. E. Gehlbach, C. R. Kennedy, J. W. Koger, et al., New developments in materials for molten-salt reactors, Nucl. Appl. Technol, 1970, 131(8), 156-169.

9 J. L. Song, Y. L. Zhao, X. J. He, B. L. Zhang, P. F. Lian, Z. J. Liu, et al., Preparation of binderless nanopore-isotropic graphite for inhibiting the liquid fluoride salt and $\mathrm{Xe}^{135}$ penetration for molten salt nuclear reactor, Carbon, 2014, 79, 36-45.
10 X. J. He, J. L. Song, L. Xu, J. Tan, H. H. Xia, B. L. Zhang, et al., Protection of nuclear graphite toward liquid fluoride salt by isotropic pyrolytic carbon coating, J. Nucl. Mater., 2013, 442(1-3), 306-308.

11 J. L. Song, Y. L. Zhao, X. J. He, B. L. Zhang, L. Xu, et al., Preparation of pyrolytic carbon coating on graphite for inhibiting liquid fluoride salt and $\mathrm{Xe}^{135}$ penetration for molten salt breeder reactor, J. Nucl. Mater., 2015, 456, 33-40.

12 X. J. He, J. L. Song, L. Xu, J. Tan, H. H. Xia, B. L. Zhang, et al., SiC coating: an alternative for the protection of nuclear graphite from liquid fluoride salt, J. Nucl. Mater., 2014, 448(1-3), 1-3.

13 B. L. Zhang, H. H. Xia, X. J. He, Z. T. He, X. D. Liu, M. W. Zhao and X. T. Zhou, Characterization of the effects of $3-\mathrm{MeV}$ proton irradiation on fine-grained isotropic nuclear graphite, Carbon, 2014, 77, 311-318.

14 L. M. Curie, V. C. Hamister and H. G. Macpherson, The production and properties of graphite for reactors, in Proceedings of the First United Nations International Conference on the Peaceful Uses of Atomic Energy, New York, 1956, vol. 8, pp. 451-473.

15 M. W. Rosenthal, R. B. Briggs and P. N. Haubenreich, Molten salt reactor program semiannual progress report, Oak Ridge National Laboratory, USA, 1973, ORNL-4832, 107-111.

16 M. W. Rosenthal, R. B. Briggs and P. R. Kasten, Molten-salt reactor program semiannual progress report, Oak Ridge National Laboratory, USA, 1967, ORNL-4191, 211-215.

17 M. W. Rosenthal, R. B. Briggs and P. R. Kasten. Molten-salt reactor program semiannual progress report, Oak Ridge National Laboratory, USA, 1969, ORNL-4344, 230-232.

18 Y. Hirohata, T. Jinushi, Y. Yamauchi, M. Hashiba, T. Hino and Y. Katoh, Gas permeability of SiC/SiC composites as fusion reactor material, Fusion Eng. Des., 2002, 61, 699-704.

19 T. Burchell, R. Bratton and W. Windes, NGNP graphite selection and acquisition strategy 2007, ORNL/TM-2007/153.

$20 \mathrm{~S}$. H. Chi and G. C. Kim, Comparison of $3 \mathrm{MeV} \mathrm{C}^{+}$ionirradiation effects between the nuclear graphites made of pitch and petroleum cokes, J. Nucl. Mater., 2008, 381, 98105.

21 Standard Practice for Neutron Radiation Damage Simulation by Charged-Particle Irradiation, ASTM E521-96 2009.

22 M. J. Shan, H. B. Wang and Z. W. Xu, Synergetic improvement of mechanical properties and surface activities in $\gamma$-irradiated carbon fibers revealed by radial positioning spectroscopy and mechanical model, Anal. Methods, 2018, 10, 496-503.

23 Z. W. Xu, Y. D. Huang and C. Y. Min, Effect of gamma-ray radiation on the polyacrylonitrile based carbon fibers, Radiat. Phys. Chem., 2010, 79, 839-843.

24 Z. W. Xu, L. Chen and L. S. Liu, Structural changes in multiwalled carbon nanotubes caused by gamma-ray irradiation, Carbon, 2011, 49, 350-351.

25 L. Chen, Z. W. Xu and J. L. Li, Modifying graphite oxide nanostructures in various media by high-energy irradiation, RSC Adv., 2014, 4, 1025-1031.

26 H. B. Wang, K. Y. Teng and C. Chen, Conductivity and electromagnetic interference shielding of graphene-based 
architectures using MWCNTs as free radical scavenger in gamma-irradiation, Mater. Lett., 2017, 186, 78-81.

27 L. Chen, Z. W. Xu and J. L. Li, Reduction and disorder in graphene oxide induced by electron-beam irradiation, Mater. Lett., 2011, 65, 1229-1230.

28 E. S. Kim and Y. W. Kim, Characterization of $3 \mathrm{MeV} \mathrm{H}^{+}$ irradiation induced defects in nuclear grade graphite, Solid State Commun., 2010, 150(35-36), 1633-1636.

29 M. Liu, W. T. Zhang, J. L. Song and H. Y. Zhang, Irradiation resistance study of binderless nanopore-isotropic graphite for use in molten salt nuclear reactors, Nucl. Eng. Des., 2018, 335, 231-240.

30 D. S. Knight and W. B. White, Characterization of diamond films by raman-spectroscopy, J. Mater. Res., 1989, 4, 385-393.

31 T. Tanabe, K. Niwase, N. Tsukuda and E. Kuramoto, On the characterization of graphite, J. Nucl. Mater., 1992, 191-194, 330-334.

32 M. S. Seehra and A. S. Pavlovic, X-Ray diffraction, thermal expansion, electrical conductivity, and optical microscopy studies of coal-based graphites, Carbon, 1993, 31, 557-564.

33 S. Ishiyama, T. D. Burchell, J. P. Strizak and M. Eto, The effect of high fluence neutron irradiation on the properties of a fine-grained isotropic nuclear graphite, J. Nucl. Mater., 1996, 230, 1-7.

34 C. Karthik, J. Kane, D. P. Butt, W. E. Windes and R. Ubic, Microstructural characterization of next generation nuclear grade graphites, Microsc. Microanal., 2012, 18, 272-278.

35 J. L. Song, Y. L. Zhao, X. J. He, B. L. Zhang and L. Xu, Helium permeability of different structure pyrolytic carbon coatings on graphite prepared at low temperature and atmosphere pressure, J. Nucl. Mater., 2016, 468, 31-36.

36 Y. Ohtsuka, J. OhashI, Y. Ueda, M. Isobe and M. Nishikawa, Erosion of Pyrolytic Graphite and Ti-doped Graphite due to High Flux Irradiation, J. Nucl. Sci. Technol., 1997, 34, 792798.

37 T. Paulmier, M. Balat-Pichelin and D. L. Quéau, Structural modifications of carbon-carbon composites under high temperature and ion irradiation, Appl. Surf. Sci., 2005, 243, 376-393.

38 B. L. Zhang, H. H. Xia, X. J. He, Z. T. He, X. D. Liu and M. W. Zhao, Characterization of the effects of $3-\mathrm{MeV}$ proton irradiation on fine-grained isotropic nuclear graphite, Carbon, 2014, 77, 311-318.

39 B. T. Kelly and D. D. L. Chung, Physics of graphite, Applied Science Publishers, 1981.

40 A. Cuesta, P. Dhamelincourt, J. Laureyns, A. Martínez-Alonso and J. Tascón, Raman microprobe studies on carbon materials, Carbon, 1994, 32, 1523-1532.

41 F. Tuinstra and J. L. Koenig, Raman spectrum of graphite, J. Chem. Phys., 1970, 53(3), 1126-1130.

42 S. Reich and C. Thomson, Philos. Trans. R. Soc. London, Ser. A, 2004, 362, 2271-2288.

43 M. A. Pimenta, G. Dresselhaus, M. S. Dresselhaus, L. G. Cançado, A. Jorio and R. Saito, Studying disorder in graphite-based systems by Raman spectroscopy, Phys. Chem. Chem. Phys., 2007, 9, 1276-1291.

$44 \mathrm{H}$. Watanabe, K. Takahashi and M. Iwaki, Structural characterization of ion implanted pyrolytic graphite, $\mathrm{Nucl}$. Instrum. Methods Phys. Res., Sect. B, 2007, 257(1-2), 549-553.

45 Z. He, H. Xia, X. Zhou, X. Yang, Y. Song and T. Wang, Raman study of correlation between defects and ferromagnetism in graphite, J. Phys. D: Appl. Phys., 2011, 44, 085001.

46 A. C. Ferrari and J. Robertson, Interpretation of Raman spectra of disordered and amorphous carbon, Phys. Rev. B: Condens. Matter Mater. Phys., 2000, 61, 14095-14107.

47 D. S. Knight and W. B. White, Characterization of Diamond Films by Raman-Spectroscopy, J. Mater. Res., 1989, 4, 385393.

48 A. C. Ferrari and J. Robertson, Resonant Raman spectroscopy of disordered, amorphous, and diamond like carbon, Phys. Rev. B: Condens. Matter Mater. Phys., 2001, 64, 075414.

49 A. C. Ferrari and J. Robertson, Origin of the $1150-\mathrm{cm}^{-1}$ Raman mode in nanocrystalline diamond, Phys. Rev. B: Condens. Matter Mater. Phys., 2001, 63(12), 121405. 